\title{
Acrokeratosis verruciformis of Hopf
}

\section{Sabah Bazouti ${ }^{1}$, Nassiba Zerrouki ${ }^{1}$, Siham Dikhaye ${ }^{1,2}$, Nada Zizi ${ }^{1,2}$}

${ }^{1}$ Department of Dermatology, Mohammed VI University Hospital of Oujda, Medical School of Oujda, Mohammed the First, University of Oujda, Oujda, Morocco, ${ }^{2}$ Epidemiology Laboratory of Research and Public Health, Oujda, Morocco

Corresponding author: Dr. Sabah Bazouti, E-mail: Sabah.bazouti@gmail.com

A 30-year-old female presented with multiple nodules, grouped, hyperkeratotic, brownish and malodorous on his feet (Fig. 1), which had been present for more than 3 years. Histopathological examination showed classical feature of "church spires” appearance without dyskeratosis (Fig. 2). Acrokeratosis Verruciformis of Hopf is a rare autosomal dominant genodermatosis. It usually develops during early childhood affecting both sexes equally. Typically, the lesions are warty to convex, brownish to skin-colored papules on the dorsa of the hands and feet, forearms and legs. Histopathologically, the lesion shows considerable hyperkeratosis, acanthosis, and papillomatosis,

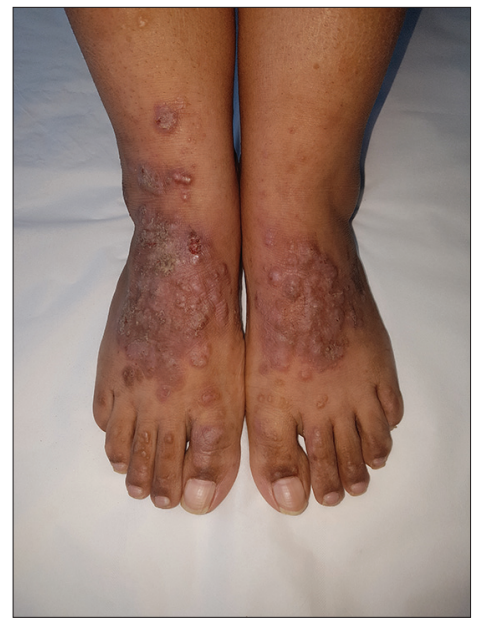

Fig 1: Multiple nodules brownish verrucous on the dorsum of the feet. mimicking a "church spire", and a thickened granular layer. It arises in early life, often at birth or infancy.

The only effective treatment of AKV is superficial ablation.

\section{CONSENT}

The examination of the patient was conducted according to the Declaration of Helsinki principles.

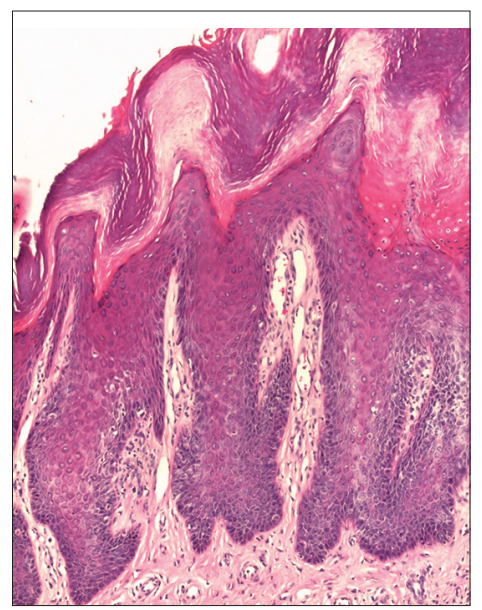

Fig 2: Hyperkeratosis and hypergranulosis with a "church spire" (H\&E, $\times 100)$.

Copyright by Sabah Bazouti, et al. This is an open access article distributed under the terms of the Creative Commons Attribution License, which permits unrestricted use, distribution, and reproduction in any medium, provided the original author and source are credited.

Source of Support: Nil, Conflict of Interest: None declared.

\footnotetext{
How to cite this article: Bazouti S, Zerrouki N, Dikhaye S, Zizi N. Acrokeratosis verruciformis of Hopf. Our Dermatol Online. 2019;10(1):93-93. Submission: 16.06.2018; Acceptance: 29.07.2018

DOI: 10.7241 /ourd.20191.27
} 